\title{
EVALUASI KINERJA FILTER CEPAT DI PDAM SIDOARJO DENGAN METODA FILTER CORING
}

\author{
EVALUATION OF RAPID FILTRATION PDAM SIDOARJO BY \\ FILTER CORING METHOD
}

\author{
Bowo D. Marsono \\ Departemen Teknik Lingkungan FTSP \\ Institut Teknologi Sepuluh Nopember (ITS), Surabaya \\ Kampus ITS Sukolilo Surabaya 60111 \\ Email : bowodjok@gmail.com
}

\begin{abstract}
Abstrak
Filter air mampu memisahkan kotoran dengan proses fisik, kimia dan biologis melalui media filter. Kualitas air yang akan didistribusi bergantung pada kinerja filter yang digunakan. Untuk itu, diperlukan evaluasi terhadap kinerja filter untuk memberikan gambaran filter saat beroperasi maupun saat backwash. Evaluasi kinerja filter cepat meliputi parameter kekeruhan filtrat, filter run volume, lama operasi filter, dan rasio volume air backwash terhadap volume air filtrat. Evaluasi backwash meliputi parameter profil kekeruhan air cucian backwash, profil kekeruhan filtrat, solid retention profile, dan ukuran media terekspansi pada saat backwash. Evaluasi backwash dilakukan dengan menggunakan metoda filter coring. Penelitian ini dilaksanakan di Instalasi Pengolahan Air Minum Taman Tirta PDAM Sidoarjo, khususnya unit filtrasi, dengan parameter kualitas air yang diperiksa adalah kekeruhan. Hasil penelitian menunjukkan bahwa kinerja filter cepat yang dievaluasi mempunyai rasio volume air backwash terhadap filtrat yang dihasilkan mencapai $2,3 \%$ atau dalam katagori baik, filter run volume mencapai $237-271 \mathrm{~m}^{3} / \mathrm{m}^{2}$ sesuai kriteria. Hasil analisa floc retention sampling dari 2 unit filter yang diteliti mencapai kekeruhan 35 - 44 NTU atau sesuai kriteria floc retention yang berarti media filter bersih. Sedangkan ekspansi media filter terdistribusi dengan baik.
\end{abstract}

Kata kunci: Filter cepat, Filter Coring, Backwash, Kekeruhan

\begin{abstract}
A water filter removes impurities from water by means of a fine physical barrier, a chemical process or a biological process. The good or bad quality of water will be distributed depends on the performance of filters used. It is necessary to evaluate the performance of the filter will provide an overview of the current filter is operating and when the filter backwash. Performance evaluation covering filtrate turbidity, filter run volume, long filter run, and the ratio of volume filter backwash to volume filtrat. Evaluations also conducted on the backwash water turbidity, filtrate turbidity profile, solid retention profile, and the size of the expanded media during backwash. Evaluation of backwash by using filter coring method. The research conducted at TamanTirta water treatment plant PDAM Sidoarjo, particularly the filtration unit, the water quality parameters examined were turbidity. From the research that has been conducted shows that the performance of the filter quickly evaluated have backwash water volume ratio of the resulting filtrate reached $2.3 \%$ or in the good category, filter run volume reached $237-271 \mathrm{~m} 3 / \mathrm{m} 2$ according to the criteria. Results of analysis of retention floc sampling of 2 units filter were 35-44 NTU or according to criteria of floc retention means clean filter media. While the expansion of the filter media properly distributed.
\end{abstract}

Keywords: Rapid Filtration, Filter Coring, Backwash, Turbidity 


\section{PENDAHULUAN}

Filter yang beroperasi telalu lama dan tidak rutin diadakan backwash dapat mengalami penyumbatan pada pori-pori media filter. Penyumbatan ini akan menyebabkan turunnya kualitas dan kuantitas effluen yang dihasilkan. Menurut Steffy dkk (2007), jika hal ini berlangsung lebih lama, maka backwash yang dilakukan pada filter tidak akan mampu untuk meremoval partikel yang berada diantara poripori media filter. Salah satu hal yang dapat dilakukan adalah mengganti media filter yang lama dengan media filter yang baru. Hal ini akan berdampak kembali membaiknya kinerja filter, akan tetapi berdampak terhadap bertambah besarnya pengeluaran yang disebabkan pembelian media filter yang tidak pada waktunya.

Sistem backwash existing pada PDAM Sidoarjo/TTS (Taman Tirta Sidoarjo) dengan menggunakan udara yang dihembuskan melalui blower, kemudian air bercampur udara, dan yang terakhir dengan air. Filter berjumlah 4 unit dengan kapasitas flow $200 \mathrm{l} / \mathrm{dt}$, dengan type single media (pasir silica) rate filtrasi $5-8 \mathrm{~m} / \mathrm{jam}$. Lama waktu backwash filter dapat mepengaruhi kinerja filter saat beroperasi. Backwash yang terlalu cepat berdampak pada tidak optimalnya removal partikel yang berada pada pori-pori media filter. Menurut Murphy (2008), backwash yang terlalu lama dapat mengakibatkan bertambah besarnya jumlah media filter yang terekspansi bersamaan dengan terekspansinya partikel-partikel yang menutup pori-pori media. Hal ini akan berdampak terhadap menurunnya ketebalan lapisan media filter.

Berdasarkan pertimbangan di atas, maka dalam penelitian ini dilakukan evaluasi terhadap kinerja filter dengan dengan penerapan metode filter coring. Menurut Pizzi (1997) Metode filter coring mempunyai beberapa kelebihan jika dibandingan dengn pengukuran yang dilakukan pada kondisi existing, dimana hanya dilakukan pengecekan pada influen dan effluent dengan menggunakan turbidity meter untuk mengukur kekeruhan. Kelebihan antara lain bisa diketahui kualitas kinerja filter secara mendetail, mulai,
Pengamatan fisik filter, Core sampling untuk solid retention profile sebelum dan sesudah backwash, Profile kekeruhan saat backwash, Pengukuran ekspansi backwash, Core sampling untuk analisa ayakan, Profile kekeruhan effluen filter, Solid retention profile. Evaluasi terhadap kinerja filter dilakukan pada unit filter di TTS (Taman Tirta Sidoarjo). Evaluasi filter dilakukan dengan menggunakan metode filter coring. Dari hasil pelaksanaan penelitian didapatkan gambaran mengenai performa filter saat beroperasi dan saat backwash berlangsung. Datadata yang diperoleh dapat digunakan sebagai bahan acuan untuk memperbaiki dan meningkatkan performa filter. Tujuan dari penelitian ini adalah mengukur kinerja filter saringan pasir cepat dan evaluasi kinerja backwash dengan penerapan metode filter coring. Menurut Bresee dan Simon (2006) kriteria kinerja filrter cepat antara lain mempunyai rasio volume air backwash terhadap volume filtrat sebesar $2-4 \%$, filter run volume sebesar $120-360 \mathrm{~m}^{3} / \mathrm{m}^{2}$. Sedangkan menurut Brouckaert dkk (2006) kriteria angka floc retention sebesar 30 - 60 NTU atau filter dalam kondisi bersih. Parameter kualitas kekeruhan menurut Permenkes Nomor 492/menkes/Per/IV/2010 tentang persyaratan air minum sebesar $\leq 5$ NTU.

Spesifikasi unit filtrasi IPAM Taman Tirta Sidoarjo adalah sebagai berikut:

$\begin{array}{ll}\text { - Jumlah Bak } & : 4 \mathrm{buah} \\ \text { - Debit filtrasi per unit } & : 50 \mathrm{~L} / \mathrm{dt} \\ \text { - Tipe Filter } & : \text { F4-19 } \\ \text { - Panjang } & : 9,75 \mathrm{~m} \\ \text { - Lebar } & : 4,90 \mathrm{~m} \\ \text { - } \text { Luar Permukaan } & : 47,8 \mathrm{~m}^{2} \\ \text { - Kecepatan Filtrasi } & : 5-8 \mathrm{~m} / \mathrm{jam} \\ \text { - Kecepatan Backwash } & : 12,5 \mathrm{~m} / \mathrm{jam} \\ \text { - Media } & : \text { single media } \\ \text { - Efektif Size (ES) } & : 0,95 \mathrm{~mm} \\ \text { - Unuformmity Coefficien }(\mathrm{UC}): 1,3 \\ \text { - Specific Grafity (SG) } & : 2,65 \\ \text { - Ketebalan Pasir } & : 0,9 \mathrm{~m} \\ \text { - Ketebalan Gravel } & : 0,1 \mathrm{~m} \\ \text { - Ukuran Efektif Pasir } & : 0,95 \mathrm{~mm} \\ \text { - Volume Pasir } & : 43 \mathrm{~m}^{3} \\ \text { - Ukuran Efektif Gravel } & : 4-7 \mathrm{~mm}^{3} \\ \text { - } \text { Volume Gravel } & : 48 \mathrm{~m}^{3}\end{array}$




\section{METODA}

\subsection{Kinerja Filter Cepat}

Menurut Bresee (2006), kinerja filter cepat diukur berdasarkan parameter kekeruhan filtrat, filter run volume, lama operasi filter, dan rasio backwash terhadap operasional filter. Rasio ini diperoleh dengan perbandingan debit aliran backwash dan debit filtrasi.

Pengukuran kekeruhan filtrat dilakukan dengan turbidimeter terhadap sampel air dari efluen unit filtrasi.

Rasio volume backwash (\%) terhadap volume filtrat dihitung dengan rumus:

$$
\frac{\text { debit backwash } \times \text { lama backwash }}{\text { debit filtrasi } x \text { lama filtrasi }} \times 100 \%
$$

Filter run volume $\left(\mathrm{m}^{3} / \mathrm{m}^{2}\right)$ dihitung dengan rumus:

$\frac{\text { debit air yang difilter }}{\text { luas permukaan bak filter }} x$ lama operasi filter

\subsection{Filter Core Sampling}

Pada penerapan metode filter core sampling ini dilakukan pengambilan sampling pada 2 bangunan filter, satu pada unit filter yang memiliki kinerja baik dan satu unit pada filter yang memiliki kinerja kurang baik.

\section{Cara pengambilan sampling:}

Berdasarkan Standard B-100 AWWA (2002) cara pengambilan sampling pada metoda core sampling adalah sebagai berikut:

1. Pilih tiga titik sampling yang dianggap mewakili.

2. Dorong pelan sampling pipa ke media dalam gerakan melingkar hingga penanda pertama baris (1 in) dan perlahan-lahan tarik pipa dengan suatu gerakan berputar-putar untuk memperdalam lubang pipa sampling.

3. Memindahkan sampel air dari pipa ke ember (min. $200 \mathrm{~mL}$ diperlukan).

4. Lanjutkan mendapatkan sampel dengan sampling, dengan hati-hati memasukkan pipa ke dalam lubang yang diciptakan oleh coring pertama. Jangan mengikis menengah dari sisi lubang karena ini akan mencemari sampel inti.

5. Ulangi proses ini sampai sampel dari berbagai kedalaman yang dikumpulkan dari tempat yang sama.

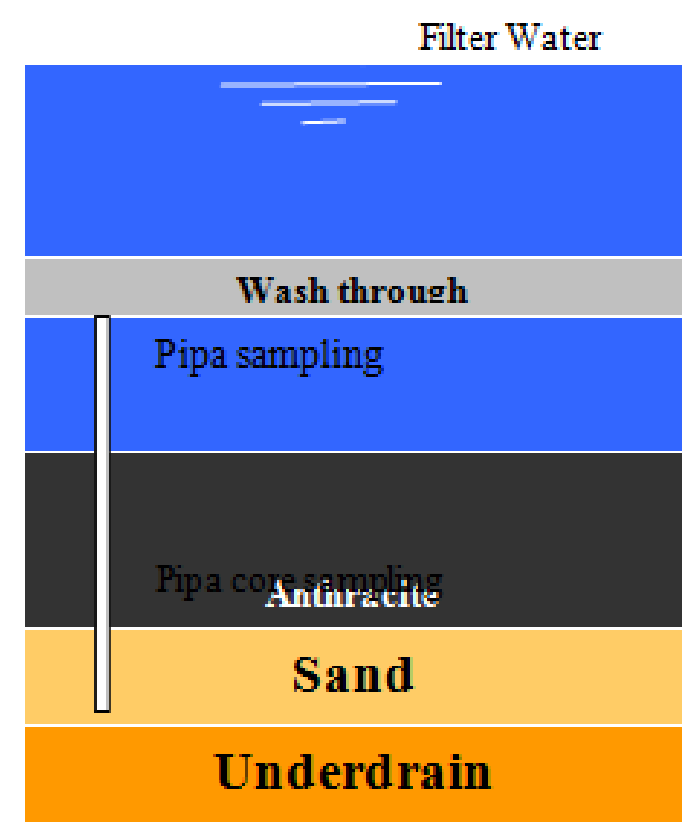

Gambar 1. Metode Core Sampling
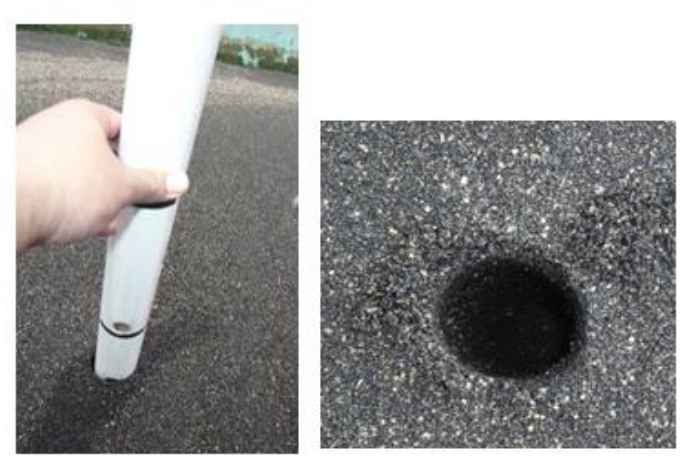

Gambar 2. Core sampling dan lubang hasil core sampling pada media filter

\subsection{Pengukur Pada saat Ekspansi Backwash}

\section{Profil kekeruhan saat backwash}

Dilakukan dengan mengukur nilai kekeruhan filter setiap 2 menit hingga backwash berhenti beroperasi. Nilai kekeruhan filter diukur dengan menggunakan turbidity meter 


\section{Pengukuran ekspansi backwash}

Dilakukan dengan meletakkan alat pengukur ekspansi media filter saat pencucian backwash.

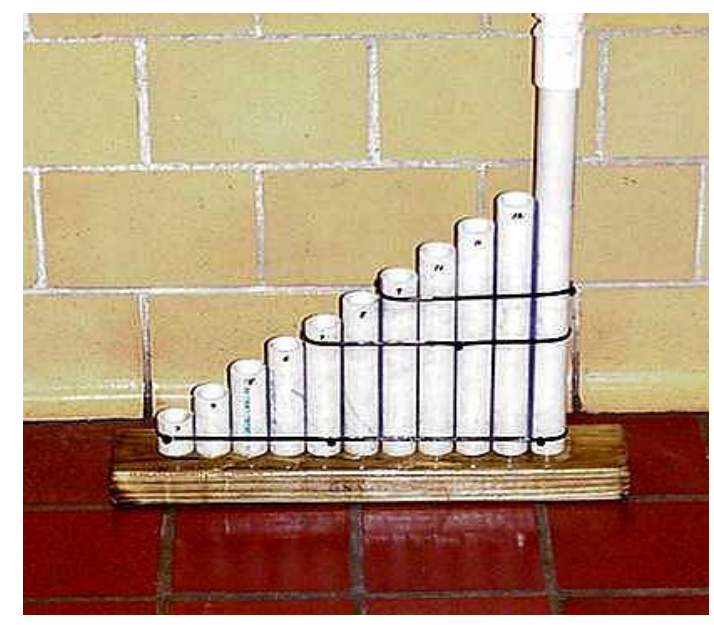

Gambar 3. Alat Pengukur Ekspansi Backwash

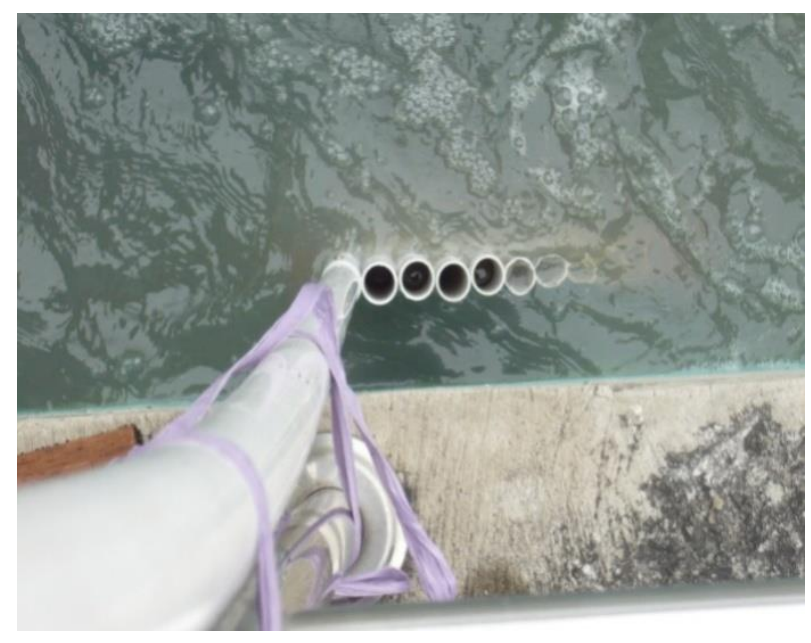

Gambar 4. Peletakan alat untuk mengukur ekspansi backwash

\section{Core sampling untuk floc retention dan analisa ayakan}

Perlakuan core sampling untuk anallisa ayakan terhadap Filter I dan IV, sebagai berikut:

1. Sampel media filter diambil dari tiga lubang penggalian pada filter dengan kedalaman 0-2 inch, 2-6 inch, dan 6-12 inch.

2. Tiap sampel pada masing-masing kedalaman diletakkan pada wadah yang berbeda

3. Ulangi percobaan hingga penggalian sampai pada bagian kerikil pada filter.
4. Selanjutnya media yang tertangkap dilakukan ayakan dan penimbangan.

\section{Profile kekeruhan effluen filter}

Dilakukan dengan mengukur besarnya kekeruhan filtrat setelah dilakukan pencucian dengan backwash untuk setiap 5 menit selama 30 menit dengan menggunakan turbidity meter.

\section{Solid retention profile}

Untuk kekeruhan media sebelum dan sesudah backwash, yaitu:

1. Siapkan $50 \mathrm{~mL}$ sampel uji core sampling menggunakan $50 \mathrm{~mL}$ gelas ukur dan pindah ke $500 \mathrm{~mL}$ labu erlenmeyer.

2. Tambahkan $100 \mathrm{ml}$ air keran dan kocok selama 30 detik. Ulangi prosedur ini sebanyak empat kali sehingga total $500 \mathrm{~mL}$ air

3. Ukur dan catat kekeruhan dari $500 \mathrm{~mL}$ air poin 2.

4. Plot kekeruhan pada berbagai kedalaman.

\section{HASIL DAN PEMBAHASAN}

\subsection{Kinerja Filter}

Pengukuran kinerja filter cepat dilakukan terhadap empat unit filter yang masing-masing mempunyai luas area $47,8 \mathrm{~m}^{2}$ dengan debit pengolahan $270 \mathrm{~m}^{3} / \mathrm{jam}$, yang berarti filter beroperasi dengan kecepatan filtrasi 5,6 $\mathrm{m}^{3} / \mathrm{m}^{2} / \mathrm{jam}$. Hasil pengukuran terhadap parameter tersebut disajikan pada Tabel 1 berikut ini.

Tabel 1. Kinerja Unit Filter Cepat

\begin{tabular}{cccc}
\hline Bak & $\begin{array}{c}\text { Kekeruhan } \\
\text { Filtrat } \\
\text { (NTU) }\end{array}$ & $\begin{array}{c}\text { Filter } \\
\text { run } \\
\text { volume } \\
\mathrm{m}^{3} / \mathrm{m}^{2}\end{array}$ & $\begin{array}{c}\text { Lama } \\
\text { Operasi } \\
\text { Filter } \\
\text { (jam) }\end{array}$ \\
\hline I & 0,69 & 237,2 & 42 \\
II & 0,64 & 254,1 & 45 \\
III & 0,62 & 259,8 & 46 \\
IV & 0,52 & 271,1 & 48 \\
\hline
\end{tabular}

Dari Tabel 1 tersebut terlihat bahwa kinerja filter terbaik pada unit no IV, sedangkan filter No. I 
berkinerja terburuk. Selanjutnya filter I dan filter IV dievaluasi dengan metoda filter coring.

Pencucian filter tersebut dengan debit aliran backwash sebesar $60 \mathrm{~m}^{3} / \mathrm{jam}$, sehingga diperoleh rasio backwash terhadap operasi filter mencapai $2,3 \%$ atau masuk dalam range kriteria $2-4 \%$.

\subsection{Profile Kekeruhan Saat Backwash}

Berdasarkan hasil analisa terhadap parameter kekeruhan air backwash bak I dan bak IV setiap 2 menit dapat ditampilkan grafik profil kekeruhan air backwash pada Gambar 5. Pada 2 menit pertama backwash kekeruhan mencapai bak I dan bak IV masing-masing 489 NTU dan 412 NTU, dan berangsur-angsur kekeruhan menurun hingga menit ke 20 mencapai 4,3 NTU dan 3,4 NTU. Hal demikian menunjukan bahwa proses pencucian filter telah berlangsung dengan hasil yang baik.

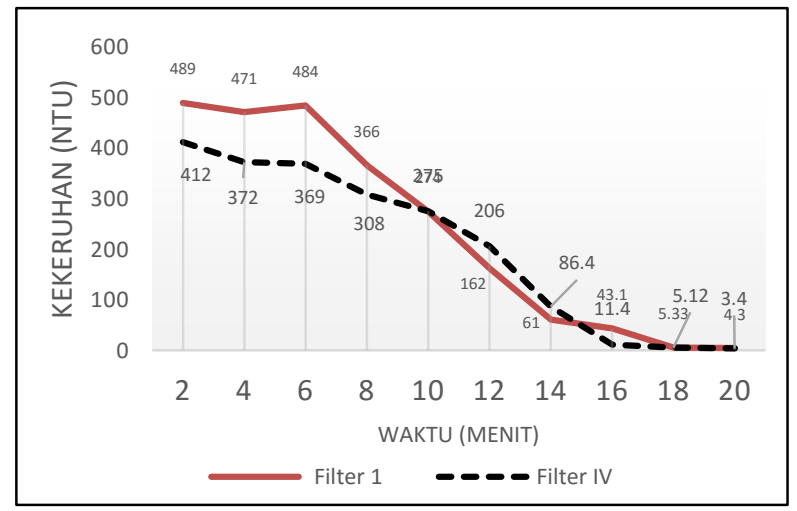

Gambar 5. Profil kekeruhan air backwash

\subsection{Profil Kekeruhan Efluen}

Indikator utama dari kinerja unit filter adalah kekeruhan filtrat, ini merupakan cara tercepat dalam mengukur efisiensi filter (Steed, 1992). Profil kekeruhan efluen filter setelah dilakukan backwash berguna untuk mengetahui bagaimana pengaruh pencucian terhadap kualitas kekeruhan filtrat. Kualitas kekeruhan diperiksa setiap lima menit sampai mencapai waktu total 30 menit. Gambar 6 berikut menunjukkan bahwa kekeruhan filtrat pada 5 menit pertama operasi filter masih menunjukkan kekeruhan 3 NTU dan menurun secara drastis pada menit ke 10 mencapai 0,8 NTU dan pada menit ke 30 mencapai 0,3 NTU.

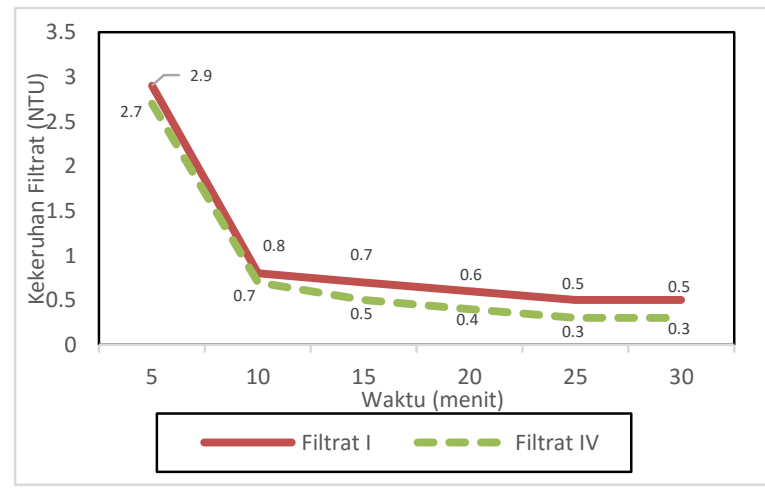

Gambar 6. Kekeruhan Filtrat Setelah Backwash

\subsection{Solid retention profile}

Evaluasi berdasarkan pengukuran solid retention profile sebelum dan sesudah backwash pada kedalaman 0-2in, 2-6 in, 6-12 in dan 12 sd. permukaan gravel dapat dilihat pada Gambar 7 dan 8 .

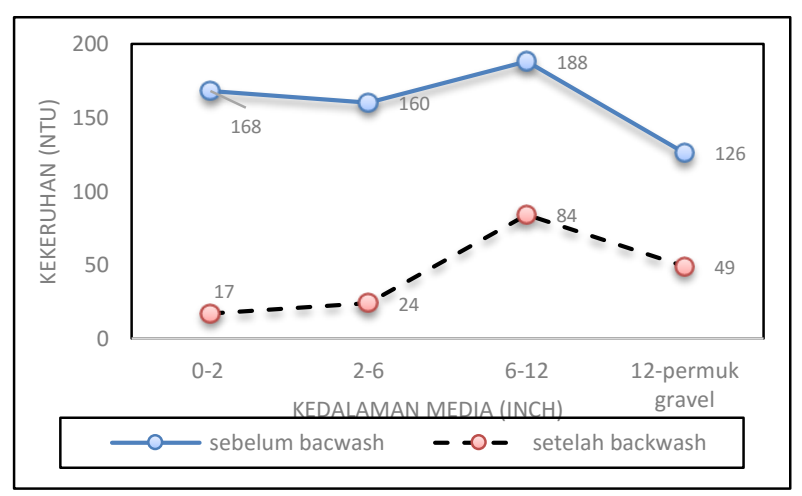

Gambar 7. Solid Retention Profile Filter I

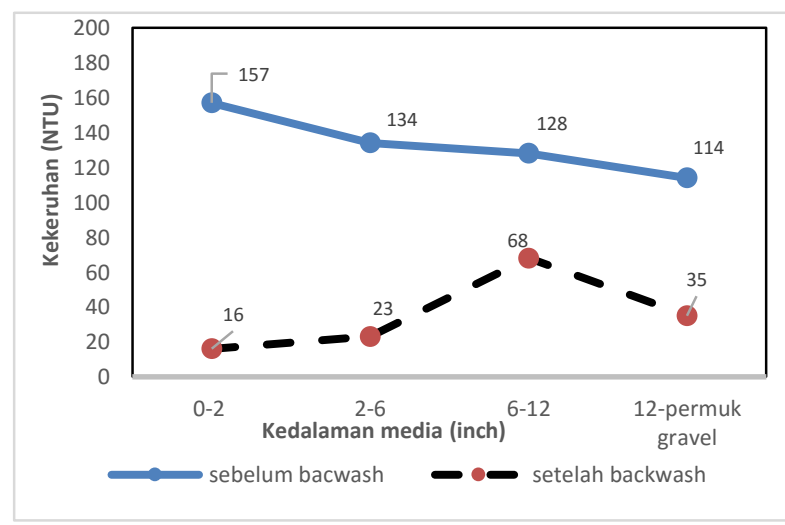

Gambar 8. Solid Retention Profile Filter IV 
Dari kedua gambar tersebut menunjukkan bahwa terjadi perubahan atau penurunan kekeruhan sebelum dan sesudah backwash. Hal demikian disebabkan pengaruh pencucian backwash dalam membersihkan flok pada media filter.

Setelah dilakukan prosedur analisa floc retention terhadap sampel setelah backwash diperoleh angka floc retention untuk bak filter I dan IV masing-masing 44 NTU dan 35 NTU atau masuk katagori media filter bersih.

\subsection{Ekspansi Backwash}

Pengukuran terhadap ekspansi backwash menunjukkan bahwa semua ukuran media dengan diameter 0,3-1.2 mm terekspansi, hal ini dibuktikan dengan masuknya media filter ke dalam alat pengukur ekspansi yang mempunyai 10 ketinggian mulai $4 \mathrm{~cm}$ sd. $40 \mathrm{~cm}$. Gambar 9 dan 10 menunjukan prosentase media terekspansi sesuai dengan ketinggiannya. Prosentase media yang tertangkap alat pada posisi ketinggian 4 dan $8 \mathrm{~cm}$ adalah media dengan ukuran $\geq 1,2 \mathrm{~mm}$, sedangkan pada ketinggian $40 \mathrm{~cm}$ ukuran media yang tertangkap alat berukuran $0,3-0,4 \mathrm{~mm}$.

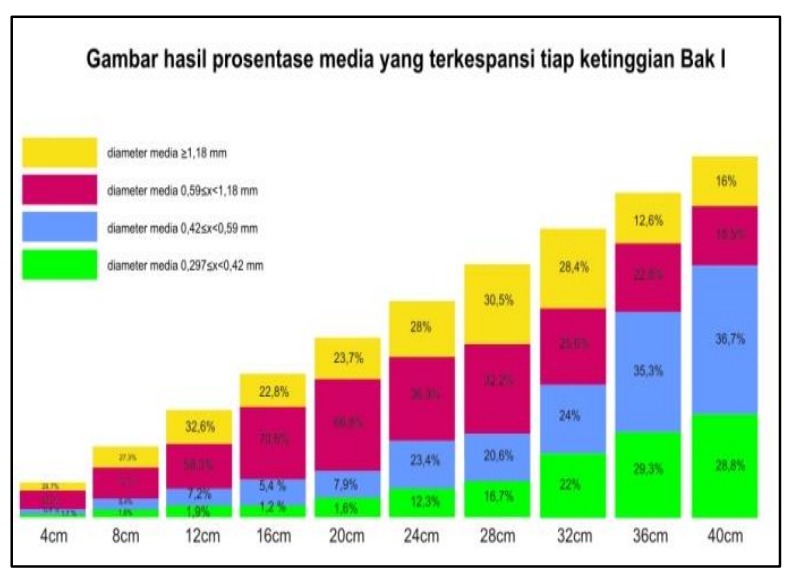

Gambar 9. Prosentase media terekspansi Filter I

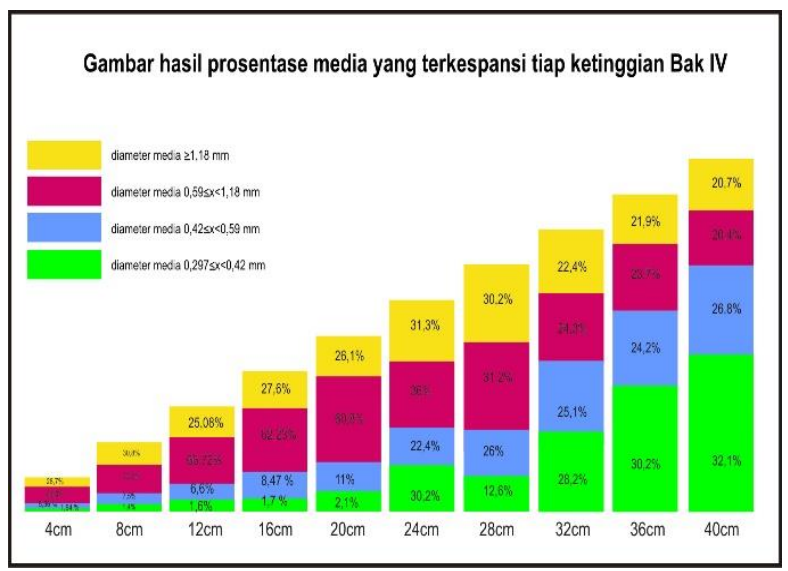

Gambar 10. Prosentase media terekspansi Filter IV

\section{KESIMPULAN}

Kesimpulan yang dapat diperoleh dalam penelitian ini adalah bahwa kinerja filter cepat yang dievaluasi mempunyai rasio volume air backwash terhadap filtrat yang dihasilkan mencapai $2,3 \%$ atau dalam katagori baik, filter run volume mencapai $237-271 \mathrm{~m}^{3} / \mathrm{m}^{2}$ sesuai kriteria. Hasil analisa floc retention sampling dari 2 unit filter yang diteliti mencapai kekeruhan 35 - 44 NTU atau sesuai kriteria floc retention yang berarti media filter bersih. Sedangkan ekspansi media filter terdistribusi dengan baik.

\section{DAFTAR PUSTAKA}

AWWA, in Ceronio1, AD, ND Basson, $\mathrm{M}$ Kruger, C Taljaard, CM Bauman, and J Haarhoff. 2002. The In-Depth Evaluation of Three Filtration Facilities. WISA

Breese, Simon. 2006. Optimizing Conventional Water Treatment Plants. Alberta Water and Wastewater Operators Association (AWWAO). Alberta 
Brouckaert, BM, A Amirtharajah, CJ Pizzi, Nick, Environmental Engineering \& Brouckaert, and JE Amburgey. 2006. Technology Inc. and Tim Wolfe, PredictingThe Efficiency of Deposit Removal During Filter Backwash. Water SA Vol.32 No.5 Montgomery

Steed, Anita, Jerry Shands, Bob Carroll. 1992. Filters and Filtration. National Rural

Brouckaert, B.M, A. Amirtharajah, R. Rajagopaul, P. Thompson. 2006. Filter Backwash Options For Rural Treatment Plants. Durban: South African Water Research Commission and National Research Foundation

Murphy, Mike. 2008. Optimizing Filter Backwashing Bergren Associates, Inc www.entechdesign.com/pdf/Optimizing\% 20Filter\%20Backwashing.pdf Water Association. United States of America

Steffy, Curt AND Bill La Dieu. 2007. Air Assisted Backwash Breath New Life Into Dying Filter Beds, Opflow, December 2007. AWWA

Kementerian Kesehatan Republik Indonesia, 2010, Permenkes No 492/MENKES/PER/IV/2010 tentang Persyaratan Kualitas Air Minum. 